\title{
Atmospheric effect on the ground-based measurements of broadband surface albedo
}

\author{
T. Manninen ${ }^{1}$, A. Riihelä ${ }^{1}$, and G. de Leeuw ${ }^{1,2}$ \\ ${ }^{1}$ Finnish Meteorological Institute, Helsinki, Finland \\ ${ }^{2}$ Department of Physics, University of Helsinki, Helsinki, Finland \\ Correspondence to: T. Manninen (terhikki.manninen@fmi.fi)
}

Received: 20 December 2011 - Published in Atmos. Meas. Tech. Discuss.: 11 January 2012

Revised: 9 October 2012 - Accepted: 10 October 2012 - Published: 12 November 2012

\begin{abstract}
Ground-based pyranometer measurements of the (clear-sky) broadband surface albedo are affected by the atmospheric conditions (mainly by aerosol particles, water vapour and ozone). A new semi-empirical method for estimating the magnitude of the effect of atmospheric conditions on surface albedo measurements in clear-sky conditions is presented. Global and reflected radiation and/or aerosol optical depth (AOD) at two wavelengths are needed to apply the method. Depending on the aerosol optical depth and the solar zenith angle values, the effect can be as large as $20 \%$. For the cases we tested using data from the Cabauw atmospheric test site in the Netherlands, the atmosphere caused typically up to $5 \%$ overestimation of surface albedo with respect to corresponding black-sky surface albedo values.
\end{abstract}

\section{Introduction}

Satellite-based surface albedo products require long-term validation using continuous surface albedo measurements, which need to be made with the highest possible accuracy and free of atmospheric influence. For example, the validation of the CM-SAF SAL (Satellite Application Facility on Climate Monitoring; Surface ALbedo; Schulz et al., 2009) product has two main strategies: large areas are validated with airborne measurements or individual pixels are validated with continuous ground-based measurement results during long periods, preferably covering seasonal variation (Riihelä et al., 2010).

The black-sky and white-sky albedo quantities represent the extreme cases under completely direct and completely diffuse illumination (Pinty et al., 2005; Román et al., 2010).
In addition, the black-sky albedo is understood to represent the situation where no atmosphere exists, i.e. it is a property of only the surface (and the illumination spectrum of the Sun). The atmospheric correction needed for the retrieval of surface albedo using satellite data has been studied for several decades and various solutions have been proposed (Martonchik et al., 1998; Strahler et al., 1999; Govaerts et al., 2006; Pinty et al., 2007; Carrer et al., 2009; Rahman and Dedieu, 1994; Lyapustin et al., 2011a,b). In addition, the influence of the sky radiance distribution, including the effect of aerosol particles, on the spectral albedo has been studied in detail (Lewis and Barnsley, 1994). The emphasis has been on the difference between the albedo values obtained in clear/partly-cloudy sky (blue-sky) or cloudy sky (white-sky) conditions and conditions without atmosphere (black-sky).

Validation of the black-sky and white-sky albedo values is complicated by the facts that (1) a satellite never observes the Earth surface in black-sky conditions, (2) ground-based continuously observing instruments do not measure the surface black-sky albedo because of the intervening atmosphere (instruments receive radiation already attenuated by the atmosphere), (3) a satellite instrument cannot detect the surface radiance in white-sky conditions because clouds obscure its view and (4) the spatial land cover heterogeneity affects the satellite-based albedo value but typically not markedly the ground-based albedo value. Spectrogoniometers can be used for black-sky albedo estimation, but then the target characteristics have to remain constant during the measurements, which take about $15 \mathrm{~min}$ or more to cover the whole hemisphere with a statistically sufficient number of individual measurements (Peltoniemi et al., 2010). Also, the blue-sky albedo can be observed by ground-based instruments, but a 
satellite-based blue-sky albedo value is a result of observed radiance and a model calculation. The quality assessment of satellite-based black-sky and white-sky albedo values is often based on estimating the accuracy of the blue-sky value and then relating this accuracy theoretically to the black-sky and white-sky albedo accuracy (Román et al., 2010).

Another alternative is to study the effect of the atmosphere on the ground-based albedo measurements separately and derive estimates for the difference between their black-sky and blue-sky albedo values. This analysis is completely independent of satellite instruments, since they are not involved at all in the estimation of the atmospheric effect. The advantage of this approach is that one does not have to tackle the effect of the atmosphere and the spatial land cover heterogeneity simultaneously when comparing satellite- and ground-based albedo estimates. In this paper we present an approach to derive the black-sky albedo directly from ground-based measurements, and the representativeness of the ground measurement site for the satellite measurements as regards surface homogeneity can be analysed independently. Especially when using a relatively coarse resolution satellite instrument, such as AVHRR, this separation of effects is important.

The broadband surface albedo is measured continuously at several permanent locations using pyranometers, for example by the BSRN network (Ohmura et al., 1998; WRCP, 2007). A pyranometer senses the heating power of broadband solar radiant flux density on a planar surface. It is designed to measure the solar radiant flux density (in watts per square metre) from a field of view of $180^{\circ}$. Instrumental error sources of pyranometers have been studied for decades and are well known (Michalsky et al., 1995; Raïch et al., 2007). Typically the spectral response is good and the cosine correction, which takes into account the difference between the angular response of a real pyranometer and the perfect cosine dependence of an ideal sensor, is essentially only needed when the solar zenith angle is larger than $60^{\circ}$. Pyranometer measurements used for the validation of satellite-retrieved surface albedo estimates require attention to levelling accuracy, non-perfect cosine response, solar zenith angle and soil moisture effects (Lucht et al., 2000a; Strahler et al., 1999). Although a lot of thorough scientific work concerning the diffuse and direct fraction of solar radiation has been carried out (e.g. Marsden et al., 2005; Pinty et al., 2005; Kaskaoutis and Kambezidis, 2009), the effect of the atmospheric optical depth on the pyranometer-measured albedo has thus far not been studied. This effect is important only when pyranometers are used for characterisation of the black-sky surface albedo, because in that case the albedo values are affected by the atmosphere due to the modification of the surface radiant flux density spectra by atmospheric absorption while also scattering, and the relative contributions of direct and diffuse radiant flux density vary with atmospheric optical depth. The main problem is varying cloud cover, but even in completely clear-sky conditions the downward spectral radiant flux density at the surface has a different shape than that at the top of atmosphere (TOA). Because the motivation for this work is to derive the atmospheric correction for ground-based measurements, which in turn are used for validation of satellite-based albedo estimates, only clear-sky cases are of interest. Since the surface albedo is generally wavelength dependent (Liang et al., 2002), the broadband albedo value measured at the surface is different from the value that one would obtain without the atmosphere (Manninen and Riihelä, 2008). In this paper we show that variations of up to $20 \%$ may occur.

This result is based on simulations of the atmospheric contribution to the surface albedo that would be measured with a ground-based pyranometer for a range of land cover types, various solar zenith angles and typical aerosol optical depth (AOD) values. The direct and diffuse radiant flux density values are obtained from the SPCTRAL2 model (Bird and Riordan, 1986; Gueymard, 1995, 2001) with the ASTM Standard G173-03 as input for the TOA solar spectral radiant flux density. A simple and robust atmospheric correction was derived by parameterization of the black-sky albedo as function of the corresponding simulated blue-sky albedo, AOD, and diffuse and direct flux densities. This formula is then applied to the broadband albedo, AOD, and direct and diffuse radiant flux density values, all measured at the BSRN Cabauw site, in order to estimate the magnitude of the atmospheric correction related to real albedo data.

The developed method offers a robust way to estimate the magnitude of the atmospheric effect on measured broadband blue-sky albedo data in cases when not enough information is available on the atmospheric characteristics to allow for the use of more refined methods. The need is obvious when using old ground-based albedo data sets, which are not always accompanied by simultaneously measured accurate atmospheric data.

\section{Materials}

\subsection{Spectral atmospheric radiation model}

The broadband surface albedo $\alpha_{\mathrm{bb}}$ is the ratio of the total reflected radiation and the incoming radiation. In practice only the shortwave part of the spectrum $(300-2500 \mathrm{~nm})$ is taken into account. Pyranometers usually measure the total radiation integrated over the bandwidth $305-2800 \mathrm{~nm}$. The surface albedo $\alpha_{\mathrm{bb}}$ is related to the solar zenith angle $\theta_{z}$, the reflected short wave radiation $R_{\mathrm{sw}}$, the total short wave radiant flux density $I_{\mathrm{sw}}$ at the surface, and the spectral albedo $\alpha(\lambda)$ via

$\alpha_{\mathrm{bb}}\left(\theta_{z}\right)=\frac{R_{\mathrm{sw}}\left(\theta_{z}\right)}{I_{\mathrm{sw}}\left(\theta_{z}\right)}=\frac{\int \alpha\left(\theta_{z}, \lambda\right) I\left(\theta_{z}, \lambda\right) d \lambda}{\int I\left(\theta_{z}, \lambda\right) d \lambda}$.

For direct and diffuse illumination, the black-sky and white-sky albedo ( $\alpha_{\text {bbdir }}$ and $\alpha_{\text {bbdiff, }}$, respectively) are related to the angular dependence of the surface reflectance 
$f_{\mathrm{r}}\left(\theta_{z}, \phi_{z}, \theta, \phi, \lambda\right)$ (i.e. the Bidirectional Reflectance Distribution Function, BRDF) via (Nicodemus, 1970; SchaepmanStrub et al., 2006)

$$
\begin{aligned}
& \alpha_{\text {bbdir }}\left(\theta_{z}\right)= \\
& \frac{\int\left(\int_{0}^{2 \pi} \int_{0}^{\pi / 2} f_{\mathrm{r}}\left(\theta_{z}, \phi_{z}, \theta, \phi, \lambda\right) \cos \theta \sin \theta d \phi d \theta\right) I_{\mathrm{dir}}\left(\theta_{z}, \lambda\right) \cos \theta_{z} d \lambda}{\int I_{\mathrm{dir}}\left(\theta_{z}, \lambda\right) \cos \theta_{z} d \lambda} \\
& \frac{\alpha_{\text {bbdiff }}=}{\int\left(\int_{0}^{2 \pi} \int_{0}^{\pi / 2} \int_{0}^{2 \pi} \int_{0}^{\pi / 2} f_{\mathrm{r}}\left(\theta_{z}, \phi_{z}, \theta, \phi, \lambda\right) \cos \theta \sin \theta I_{\mathrm{diff}}\left(\theta_{z}, \lambda\right) \cos \theta_{z} \sin \theta_{z} d \phi d \theta d \phi_{z} d \theta_{z}\right) d \lambda} \\
& \int\left(\int_{0}^{2 \pi} \int_{0}^{\pi / 2} I_{\text {diff }}\left(\theta_{z}, \lambda\right) \cos \theta_{z} \sin \theta_{z} d \phi_{z} d \theta_{z}\right) d \lambda
\end{aligned}
$$

where the BRDF describes which fraction of the reflected radiation coming from direction $\left(\theta_{z}, \phi_{z}\right)$ is reflected to the direction $(\theta, \phi)$, where $\theta_{z}$ and $\phi_{z}$ are the solar zenith and azimuth angles, and $\theta$ and $\phi$ are the zenith and azimuth angles of the viewing direction. The BRDF is not typically a strong function of the wavelength, but slightly different values are often obtained for the visible and near-infrared wavelengths. The blue-sky albedo $\alpha_{\mathrm{bb}}$ is then

$\alpha_{\mathrm{bb}}\left(\theta_{z}\right)=d \alpha_{\text {bbdir }}\left(\theta_{z}\right)+(1-d) \alpha_{\text {bbdiff }}$,

where $d$ is the fractional amount of direct radiant flux.

If there is no atmosphere, the radiant flux density used in Eq. (1) is the top of atmosphere solar spectral radiant flux density $I_{0}(\lambda)$ (ASTM Standard G-173-03) and the broadband albedo would be the black-sky albedo $\alpha_{0_{\mathrm{bb}}}$. However, the presence of aerosol particles, water vapour and gases in the atmosphere requires that both the direct and diffuse contributions to the radiant flux density at the surface are taken into account.

Surface albedo values measured at grazing incidence angles are typically prone to error, and therefore values measured at solar zenith angles larger than $70^{\circ}$ are usually discarded from analysis. For smaller solar zenith angles, the attenuation by the atmosphere can quite accurately be taken into account by assuming that the light propagates in the atmosphere along a straight path. Then the direct solar radiant flux density on a surface normal to the direction of the Sun at ground level $I_{\mathrm{dir}}\left(\theta_{z}, \lambda\right)$ for wavelength $\lambda$ is related to the radiant flux density at the top of the atmosphere $I_{0}(\lambda)=H_{0}(\lambda) D$ by (Bird and Riordan, 1986)

$$
\begin{aligned}
I_{\text {dir }}\left(\lambda, \theta_{z}\right)= & H_{0}(\lambda) D T_{\mathrm{r}}\left(\lambda, \theta_{z}\right) T_{\text {Aer }}\left(\lambda, \theta_{z}\right) T_{\mathrm{w}}\left(\lambda, \theta_{z}\right) \\
& T_{\mathrm{o}}\left(\lambda, \theta_{z}\right) T_{\mathrm{u}}\left(\lambda, \theta_{z}\right),
\end{aligned}
$$

where $H_{0}$ is the extra-terrestrial radiant flux density at the mean Earth-Sun distance for wavelength $\lambda ; D$ is the correction factor for the Earth-Sun distance; and $T_{\mathrm{r}}, T_{\text {Aer }}, T_{\mathrm{w}}, T_{\mathrm{o}}$ and $T_{\mathrm{u}}$ are the transmittance functions of the atmosphere for molecular (Rayleigh) scattering, aerosol attenuation, water vapour absorption, ozone absorption, and uniformly mixed gas absorption, respectively. The direct irradiance on a horizontal surface is obtained by multiplying Eq. (5) by $\cos \theta_{z}$. The aerosol transmittance is
$T_{\text {Aer }}\left(\lambda, \theta_{z}\right)=\exp \left(-\tau_{\text {Aer }}(\lambda) / \cos \theta_{z}^{\prime}\right)$

where (Bird and Riordan, 1986)

$\cos \theta_{z}^{\prime}=\cos \theta_{z}+0.15\left(93.885-\cos \theta_{z}\right)^{-1.253}$

and $\tau_{\text {Aer }}(\lambda)$ is the aerosol optical depth (AOD) at wavelength $\lambda$. The AOD wavelength dependence is described by a power law (Ångström, 1929)

$\tau_{\text {Aer }}(\lambda)=\beta \cdot \lambda^{-\alpha_{\mathrm{A}}}=\tau_{\text {Aer }}\left(\lambda_{\text {ref }}\right) \cdot\left(\frac{\lambda}{\lambda_{\text {ref }}}\right)^{-\alpha_{\mathrm{A}}}$,

where $\beta$ is the AOD at the reference wavelength $\lambda_{\text {ref }}$ (usually taken at $1 \mu \mathrm{m})$ and $\alpha_{\mathrm{A}}$ is the Angström exponent evaluated for the wavelength pair $\lambda_{1}$ and $\lambda_{2}$. The set of $\tau_{\text {Aer }}$ and corresponding $\alpha_{\mathrm{A}}$ and $\beta$ values used in this study are given in Table 1.

To calculate the direct and diffuse solar radiant flux densities at the surface per unit area $\left(I_{\text {dir }}(\lambda)\right.$ and $\left.I_{\text {diff }}(\lambda)\right)$, detailed atmospheric measurements are required together with the albedo measurements. In this study we consider only clear-sky cases. Ground-based surface albedo measurements are usually not accompanied by simultaneous detailed atmospheric measurements, which would allow for an accurate atmospheric correction. Hence, a parameterization is developed using computations with a relatively simple but informative radiative transfer model which requires using only a limited and readily available number of atmospheric parameters. The model SPCTRAL2 (Bird and Riordan, 1986; Gueymard, 1995, 2001) was chosen for that reason.

The estimation of the diffuse solar radiant flux density at the surface $\left(I_{\text {diff }}(\lambda)\right)$ is much more complex than the estimation of the direct solar radiant flux because it contains components related to the interaction between the atmosphere and the surface. Aerosols affect the direct and diffuse components of the radiant flux density in opposite ways. The larger the AOD, the smaller the amount of direct radiation reaching the surface is, but the larger the proportion of the diffuse radiation. The atmospheric effect is most evident at the shortest wavelengths because the AOD is usually largest at the shorter wavelengths. Also, the increase of the solar zenith angle results in decrease of the direct radiant flux density and increase of the fraction of diffuse radiant flux density due to the longer atmospheric path.

The diffuse radiant flux density computed in SPCTRAL2 consists of three components: (1) Rayleigh scattering, (2) aerosol scattering and (3) a component that accounts for multiple scatterings of light between the ground and the atmosphere. The diffuse radiant flux density component contains separate transmittance terms for ozone, water vapour, mixed gas, aerosol absorption and aerosol scattering.

\subsection{Cosine effect of pyranometer measurements}

The difference of the true blue-sky albedo value $\alpha_{\mathrm{bb}}$ and that observed by the pyranometer depends on the cosine of the 
Table 1. The values of the aerosol optical depth $\tau_{\text {Aer }}$ at wavelengths $440 \mathrm{~nm}$ and $870 \mathrm{~nm}$ used in the simulations. The corresponding Ångström parameter values $\alpha$ and $\beta$ are given as well. The first row corresponds to the standard atmosphere ASTM Standard G173-03.

\begin{tabular}{|c|c|c|c|}
\hline$\tau_{\text {Aer }}$ at $440 \mathrm{~nm}$ & $\tau_{\text {Aer }}$ at $870 \mathrm{~nm}$ & $\alpha$ & $\beta$ \\
\hline 0.27 & 0.0729 & $1.92 \mathrm{E}+00$ & 0.0558 \\
\hline 0.1 & 0.03 & $1.77 \mathrm{E}+00$ & 0.0235 \\
\hline 0.1 & 0.05 & $1.02 \mathrm{E}+00$ & 0.0434 \\
\hline 0.1 & 0.075 & $4.22 \mathrm{E}-01$ & 0.0707 \\
\hline 0.1 & 0.099 & $1.47 \mathrm{E}-02$ & 0.0988 \\
\hline 0.25 & 0.075 & $1.77 \mathrm{E}+00$ & 0.0586 \\
\hline 0.25 & 0.125 & $1.02 \mathrm{E}+00$ & 0.108 \\
\hline 0.25 & 0.188 & $4.22 \mathrm{E}-01$ & 0.177 \\
\hline 0.25 & 0.248 & $1.47 \mathrm{E}-02$ & 0.247 \\
\hline 0.5 & 0.15 & $1.77 \mathrm{E}+00$ & 0.117 \\
\hline 0.5 & 0.25 & $1.02 \mathrm{E}+00$ & 0.217 \\
\hline 0.5 & 0.375 & $4.22 \mathrm{E}-01$ & 0.354 \\
\hline 0.5 & 0.495 & $1.47 \mathrm{E}-02$ & 0.494 \\
\hline 0.75 & 0.225 & $1.77 \mathrm{E}+00$ & 0.176 \\
\hline 0.75 & 0.375 & $1.02 \mathrm{E}+00$ & 0.325 \\
\hline 0.75 & 0.563 & $4.22 \mathrm{E}-01$ & 0.530 \\
\hline 0.75 & 0.75 & $9.78 \mathrm{E}-04$ & 0.749 \\
\hline 1 & 0.3 & $1.77 \mathrm{E}+00$ & 0.235 \\
\hline 1 & 0.5 & $1.02 \mathrm{E}+00$ & 0.434 \\
\hline 1 & 0.75 & $4.22 \mathrm{E}-01$ & 0.707 \\
\hline 1 & 0.99 & $1.47 \mathrm{E}-02$ & 0.988 \\
\hline 1.25 & 0.375 & $1.77 \mathrm{E}+00$ & 0.293 \\
\hline 1.25 & 0.625 & $1.02 \mathrm{E}+00$ & 0.542 \\
\hline 1.25 & 0.938 & $4.22 \mathrm{E}-01$ & 0.884 \\
\hline 1.25 & 1.25 & $5.87 \mathrm{E}-04$ & 1.249 \\
\hline 1.5 & 0.45 & $1.77 \mathrm{E}+00$ & 0.352 \\
\hline 1.5 & 0.75 & $1.02 \mathrm{E}+00$ & 0.651 \\
\hline 1.5 & 1.125 & $4.22 \mathrm{E}-01$ & 1.061 \\
\hline 1.5 & 1.495 & $4.90 \mathrm{E}-03$ & 1.494 \\
\hline 1.75 & 0.525 & $177 \mathrm{E}+00$ & 0.411 \\
\hline 1.75 & 0.875 & $1.02 \mathrm{E}+00$ & 0.759 \\
\hline 1.75 & 1.313 & $4.22 \mathrm{E}-01$ & 1.238 \\
\hline 1.75 & 1.75 & 4.19E-04 & 1.749 \\
\hline 2 & 0.6 & $1.77 \mathrm{E}+00$ & 0.469 \\
\hline 2 & 1 & $1.02 \mathrm{E}+00$ & 0.868 \\
\hline 2 & 1.5 & $4.22 \mathrm{E}-01$ & 1.414 \\
\hline 2 & 1.98 & $1.47 \mathrm{E}-02$ & 1.976 \\
\hline
\end{tabular}

solar zenith angle value (Michalsky et al., 1995; Raïch et al., 2007). The uncorrected global radiant flux density is the sum of the direct $I_{\text {dir }}$ and diffuse $I_{\text {diff }}$ radiant flux density values. The radiant flux density $I_{\mathrm{c}}$ with the cosine effect taken into account is obtained from

$I_{\mathrm{c}}=\left(1+\frac{I_{\mathrm{diff}}}{1367 \cos \theta_{z}}\right) I_{\mathrm{dir}} C_{\mathrm{bTP}}+\left(1-\frac{I_{\mathrm{dir}}}{1367 \cos \theta_{z}}\right) I_{\mathrm{diff}} C_{\mathrm{dTP}}$

The value of the correction coefficient $C_{\mathrm{dTP}}$ is 0.9789 , and the correction coefficient $C_{\mathrm{bTP}}$ values for all solar zenith angles were in this study interpolated/extrapolated from those at solar zenith angles of $0,10,20,30,40,50,60$ and $70^{\circ}$. The mean Earth-Sun distance was used in the simulations to assess the typical size of a cosine effect. Taking into account the variation of the Earth-Sun distance (Bird and Riordan, 1986) would alter the estimated radiant flux density $I_{\mathrm{c}}$ by less than $\pm 2.5 \%$. The size of the cosine correction here is expected to be typical of the older sensor types. The data of this study, based on CM22 pyranometers, does not need a cosine correction.

\subsection{Data}

87 individual reflectance spectra of diverse land cover types which were selected from the USGS Spectroscopy Lab data base for the atmospheric simulations: 10 for grass, 19 for forest, 5 for crop, 6 for lichen, 4 for minerals, 18 for man-made materials, 4 for water, 8 for snow/ice and 13 for mixtures of rock, etc. (Clark et al., 2007). The spectra are shown in Fig. 1.

Aerosol and albedo data was obtained from the Cabauw Experimental Site for Atmospheric Research (CESAR) $\left(\mathrm{CBW}, 51^{\circ} 18^{\prime} 15^{\prime \prime} \mathrm{N}, 04^{\circ} 55^{\prime} 37^{\prime \prime} \mathrm{E},-1 \mathrm{~m}\right.$ a.s.l., The Netherlands), which is located in flat terrain in the centre of The Netherlands. The surrounding area consists mainly of grassland interrupted by narrow ditches. At the site, which is owned and supervised by KNMI, a consortium of eight Dutch institutes has collectively brought together a suite of instrumentation for atmospheric research, including landatmosphere interaction and cloud, aerosol and radiation interaction. The site consists of a $213 \mathrm{~m}$ tall meteorological tower, a remote sensing terrain, a BSRN station and a field for micro-meteorological observations. High quality radiation observations are performed at the BSRN station including an AERONET CIMEL Sun photometer.

AOD is measured at Cabauw using the CIMEL Sun photometer at four wavelengths $(440,675,870$ and $1020 \mathrm{~nm})$ and data are available via AERONET (Holben et al., 1998). The data are cloud-screened and quality-controlled (Level 2.0). In this paper we used data for the period January-July 2007. In this period the mean value of the AOD at $440 \mathrm{~nm}$ was 0.33 with a standard deviation of $74 \%$. The corresponding values for $870 \mathrm{~nm}$ were 0.16 and $73 \%$. A wide variation of the AOD is observed, which allows for studying the effect of the AOD and the solar zenith angle (using the seasonal variation) separately. The maximum AOD values are very high (1.96 and 1.17 at $440 \mathrm{~nm}$ and $870 \mathrm{~nm}$, respectively), thus the data set can be used to demonstrate the effect for a range of aerosol concentrations. The AOD values measured in Cabauw were used as the basis for selecting the AOD range used in the simulation of the atmospheric effect.

One-minute averages of the direct and diffuse solar radiant flux densities measured at BSRN Cabauw were used to estimate the difference between blue- and black-sky albedo in situations when AOD was available (Knap, 2011). Broadband albedo is measured in Cabauw using Kipp \& Zonen CM22 pyranometers with a time resolution of $10 \mathrm{~min}$ (Knap, 2012). No cosine correction was needed for the data. The mean of the albedo was 0.25 with a standard deviation of 

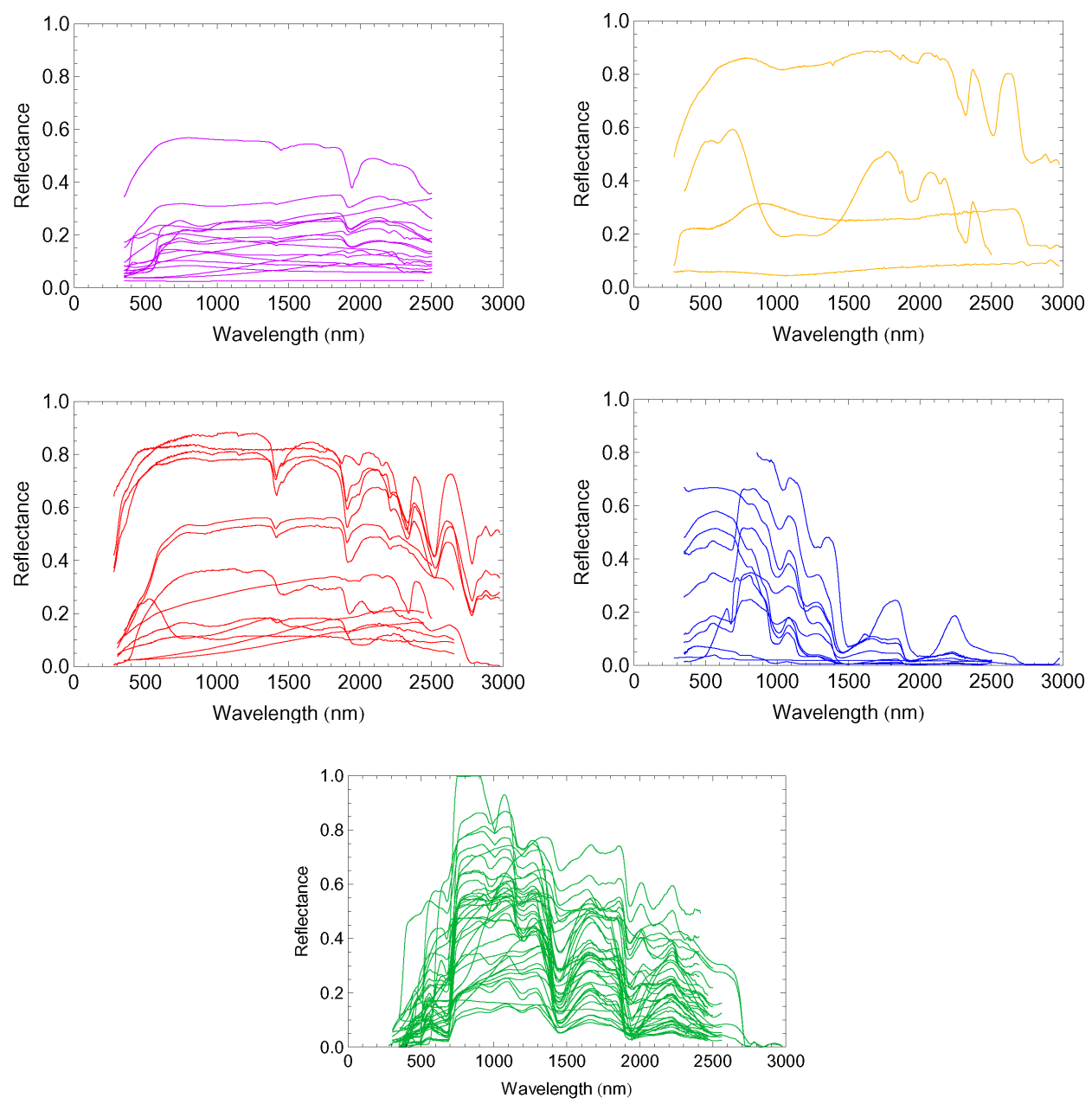

Fig. 1. Reflectance spectra used in the study (Clark et al., 2007). The blue curves represent snow and water, the green curves vegetation, the red curves mixtures, the yellow curves minerals and the lilac curves man-made targets. The snow/water curves contain examples of various melting snow cases, ice and sea water. The vegetation curves contain examples of various tree species, flowers, weeds and grass. The mixture curves contain examples of various rocks, such as basalt and limestone. The mineral curves contain dolomite, magnetite and labradorite sample spectra. The man-made target curves are various kinds of asphalt, bricks, roof tar, roofing felt, tar paper, concrete, wood beam and dust debris.

$7.1 \%$. The mean values and standard deviations for the AOD at wavelengths of 440 and $870 \mathrm{~nm}$ corresponding to the existing solar radiant flux values were 0.35 and $69 \%$ and 0.16 and $78 \%$, respectively.

There is no obvious correlation between the surface albedo and the AOD values, so the seasonal variation of the surface and the atmospheric aerosol load are relatively independent. Thus, the data set of Cabauw is well suited for testing the estimation of the effect of the atmosphere on the measured broadband surface albedo.

\section{Simulation of the atmospheric effect on the broadband surface albedo}

Simulations of the atmospheric effect on the broadband surface albedo were carried out using the SPCTRAL2 model
(Bird and Riordan 1986; Sect. 2.1) and the 87 USGS Spectroscopy Lab land cover spectra and aerosol optical depth values varying in the range observed in Cabauw (Sect. 2.3). The presence of aerosol was accounted for by using the AOD values, at wavelengths of 440 and $870 \mathrm{~nm}$, given in Table 1 . The maximum value for the AOD at $440 \mathrm{~nm}$ was taken to be roughly the highest value observed at Cabauw. The maximum AOD value at $870 \mathrm{~nm}$ was then taken to be similar to that at $440 \mathrm{~nm}$. Ozone was included in the simulations for three different concentrations: $0.25,0.35$ and $0.5 \mathrm{~atm}-\mathrm{cm}$. Water vapour was accounted for by using the following three concentrations: $0.5,2$ and $3.5 \mathrm{~cm}$ of precipitable in a vertical path. The solar zenith angle values used in the simulations were $0,10,20,30,40,50,60$ and $70^{\circ}$. All combinations of the 87 spectra, 37 AOD combinations, 3 ozone values, 

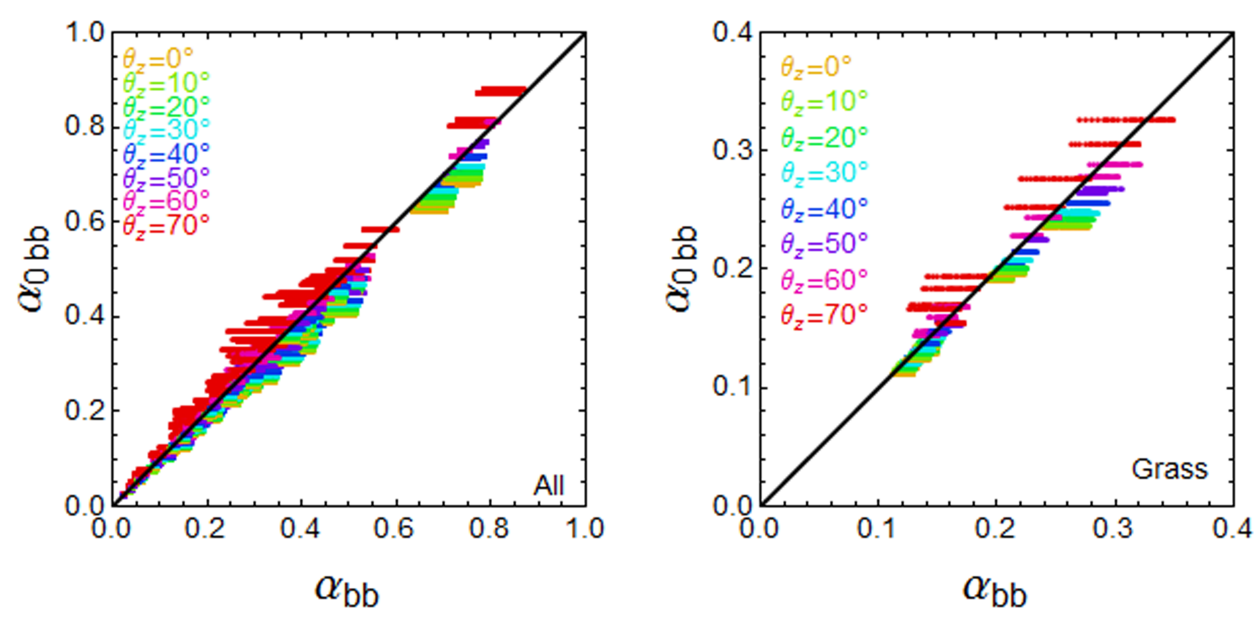

Fig. 2. The calculated black-sky albedo $\alpha_{0_{\mathrm{bb}}}$ versus corresponding simulated pyranometer measurements $\alpha_{\mathrm{bb}}$ of the surface albedo for all 87 land cover spectra (left panel) and all 9 grass spectra (right panel) for all 333 atmosphere parameter combinations studied. The solar zenith angle values $\theta_{z}$ are colour coded as indicated in the legend.

3 water vapour values and 8 solar zenith angle values were simulated, resulting in altogether 231768 individual cases.

The simulated blue-sky broadband albedo $\alpha_{\mathrm{bb}}$ was obtained using the sum of the modelled direct $I_{\text {dir }}$ and diffuse $I_{\text {diff }}$ radiant flux densities for the radiant flux density $I_{\mathrm{sw}}$ in Eq. (1). The required reflectance spectra were directly derived from the USGS Spectroscopy Lab data base (Clark et al., 2007). Then only the BRDF was needed to obtain the surface albedo estimate. At this stage the idea was to simulate the variation range of the atmospheric effect for a chosen example set of land cover spectra which covers the wide variation of typical land cover types. Therefore, it was not critical to have the BRDF description for the chosen individual model targets, which are just random representatives of similar targets, but the BRDF descriptions had to be realistic both in size and in characteristics. In addition, as the same BRDF values were used for the black-sky albedo to which the results were compared, the effect of the BRDF is even less important. The BRDF values were obtained using the methods developed for visible and near-infrared bands of satellite instruments (Roujean et al., 1992; Wu et al., 1995). The spectra were split into a visible and and near-infrared part separated at $750 \mathrm{~nm}$.

The corresponding black-sky albedo values were calculated using the same surface description as for the blue-sky albedo calculation, but $I_{\text {dir }}$ in Eq. (2) was taken to be the TOA radiant flux value. The total, visible and near-infrared radiant flux density values $\left(I_{0_{\mathrm{sw}}}, I_{0_{\text {vis }}}\right.$, and $\left.I_{0_{\text {nir }}}\right)$ at the top of the atmosphere were obtained by integrating the solar radiant flux density spectra (ASTM Standard G173-03) over 305-750 nm for the visible band and over $750-2500 \mathrm{~nm}$ for the nearinfrared band. Pyranometers usually measure the radiant flux density integrated over the band $305-2800 \mathrm{~nm}$; however, neglecting the contribution of the band $2500-2800 \mathrm{~nm}$ is justified since the radiant flux density in that band is negligible
$(<0.2 \%)$ as compared to the whole radiant flux density or that in the near-infrared band.

This data set was used to develop a method for estimating the effect of the atmosphere on the pyranometer-based albedo measurements.

\section{Results}

\subsection{Simulations}

The calculated broadband black-sky albedo $\alpha_{0_{\mathrm{bb}}}$ is shown in Fig. $2 \mathrm{a}$ as a function of the simulated blue-sky albedo $\alpha_{\mathrm{bb}}$. Data for all land cover types, solar zenith angles and AOD values are included. The results for the different solar zenith angles are colour-coded, but the land cover types or AOD values are not specified. As an example, the results over grass are presented in Fig. 2b. The horizontal lines in Fig. 2 are caused by the AOD, which affects the blue-sky albedo but not the black-sky albedo. The strong variation of the bluesky albedo for the range of AODs studied here clearly shows the importance of atmospheric correction for black-sky measurements. The results over a single surface (grass, Fig. 2b) are similar. Although the effect of the atmosphere is not large for the standard atmosphere (ASTM Standard G173-03) (Table 1), the whole range of AOD values causes a drastic variation in the simulated values.

The relative difference between the simulated blue-sky surface albedo and the corresponding black-sky albedo, i.e. $\left(\alpha_{\mathrm{bb}}-\alpha_{0_{\mathrm{bb}}}\right) / \alpha_{0_{\mathrm{bb}}}$, is plotted in Fig. 3 as a function of the simulated blue-sky albedo for the whole data set and separately for different solar zenith angles. The relative difference clearly depends on the solar zenith angle; at small solar zenith angles the blue-sky albedo is mostly smaller than the corresponding black-sky albedo, but at a solar zenith angle of 

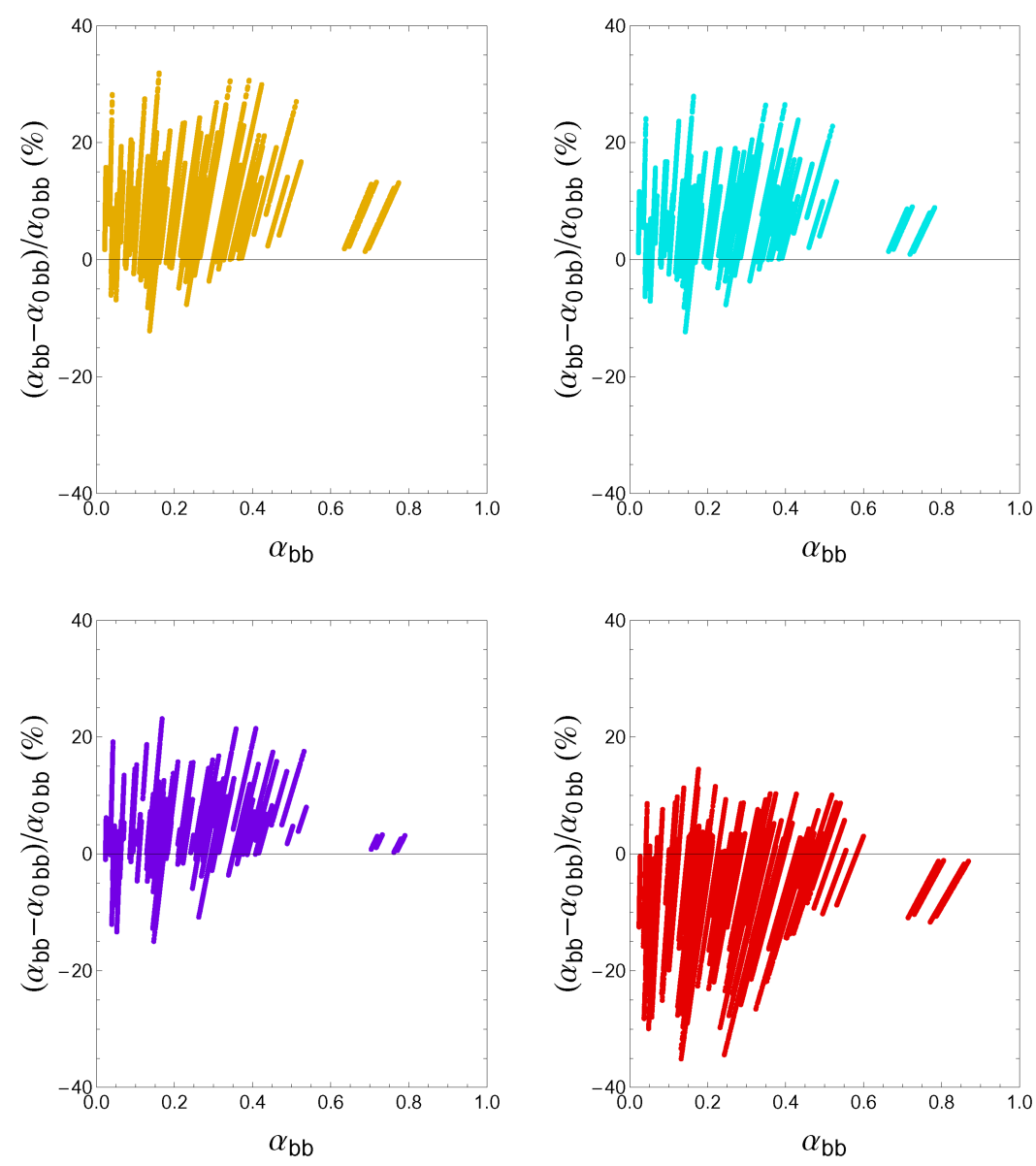

Fig. 3. The simulated relative difference of the blue-sky albedo $\alpha_{\mathrm{bb}}$ and black-sky albedo $\alpha_{0_{\mathrm{bb}}}$ values versus the blue-sky surface albedo $\alpha_{\mathrm{bb}}$ for all 87 land cover spectra used in the studied atmospheres for solar zenith angle values $0^{\circ}$ (top left panel), $30^{\circ}$ (top right panel), $50^{\circ}$ (bottom left panel) and $70^{\circ}$ (bottom right panel).

$70^{\circ}$ the blue-sky value is mostly the larger of the two. This is in accordance with previous studies (Lucht et al., 2000b). The range of variation of the relative differences is similar for all angles. The effect of the atmosphere can be more than $20 \%$.

The ratios of the calculated blue-sky and black-sky albedo values versus the aerosol optical depth at $440 \mathrm{~nm}$ and the diffuse radiant flux density are shown in Fig. 4 for the whole data set used in the simulations. These results will be used in designing the regression formulas of Sect. 4.2.

The atmospheric optical depth usually decreases with increasing wavelength. Therefore, the radiant flux density is less attenuated at near-infrared than shorter wavelengths, and the irradiance spectrum at the surface is different from that at TOA with relatively larger attenuation at wavelengths in the UV/VIS than in the NIR range. On the other hand, for most of the studied reflectance spectra (Fig. 1) the reflectance is higher in the near-infrared region than in the visible region. Smaller attenuation and higher reflectance in the nearinfrared wavelengths leads to higher broadband albedo estimates than would occur without the atmospheric effect. The only target which systematically has a clearly smaller reflectance in the near-infrared band than in the visible band was snow, which has the highest broadband albedo values of the whole data set. Accordingly, snow albedo $\left(\alpha_{\mathrm{bb}}\right.$ value $>0.6$ in Fig. 3) was mostly less overestimated in low solar zenith angle cases.

The simulations have been made with the assumption of an ideal pyranometer. In practice, sometimes a cosine correction is needed for large solar zenith angle values (Sect. 2.2) and typically leads to a reduction of the true albedo (Michalsky et al., 1995). Hence, the cosine correction would shift the relative differences for a solar zenith angle of $70^{\circ}$ (Fig. 3b) a few percent upward.

The relative difference in the blue-sky and black-sky surface albedo values due to differences only in ozone or water vapour amounts was on average smaller than $0.3 \%$, and in $95 \%$ of the simulated cases it was smaller than $0.8 \%$. 

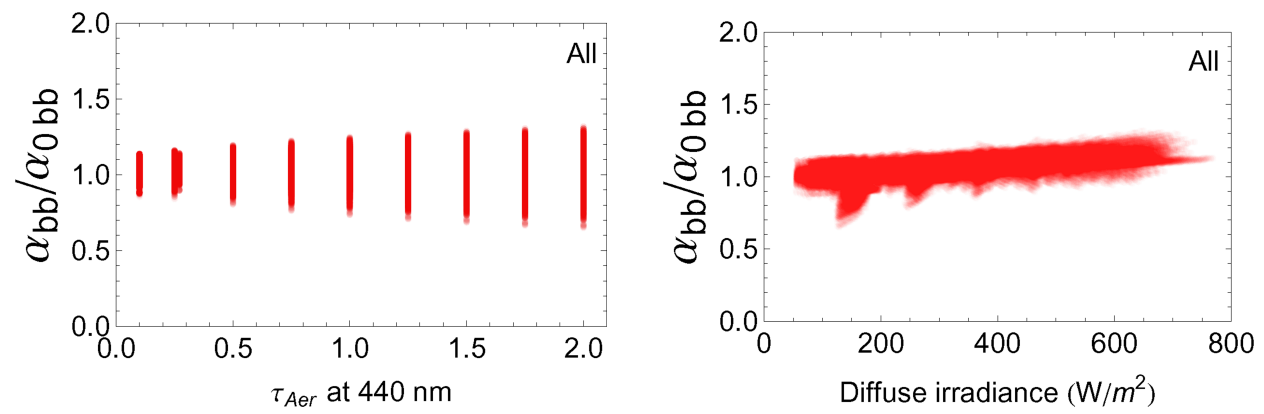

Fig. 4. Ratio of the calculated blue-sky and black-sky albedo values versus the aerosol optical depth at $440 \mathrm{~nm}$ (left panel) and the diffuse radiant flux density amount (right panel).

\subsection{Regression formulas}

The data presented above clearly demonstrate the complex relation between the black- and blue-sky broadband surface albedos. Due to the complex nature of the diffuse radiation component (Bird and Riordan, 1986) and the varying shapes of the diverse land cover type spectra (Fig. 1), it is not possible to derive a simple analytic relationship between the black-sky surface albedo $\alpha_{0_{\mathrm{bb}}}$ and the blue-sky albedo $\alpha_{\mathrm{bb}}$. To provide a correction which takes into account the atmospheric effect, an empirical regression between the blackand blue-sky surface albedo of the form $\alpha_{\mathrm{bb}}(1+\ldots)$ was sought. The parameters included were the AOD values at two wavelengths ( $\tau_{440}$ and $\tau_{870}$ ), the solar zenith angle $\left(\theta_{z}\right)$ and the direct $\left(I_{\text {dir }}\right)$ and diffuse $\left(I_{\text {diff }}\right)$ radiant flux densities. The mathematical formulation of the correlation is sought to resemble expressions in the diffuse radiation components (Bird and Riordan, 1986) and the observed relationships (Fig. 4). The obtained relationship is

$$
\begin{aligned}
& \hat{\alpha}_{0_{\mathrm{bb}}}=\alpha_{\mathrm{bb}}\left[c_{0}+c_{1} \frac{\left(1-\exp \left(-\tau_{440} / \cos \theta_{z}\right)\right)}{1-\alpha_{\mathrm{bb}}}\right. \\
& +c_{2} \frac{\left(1-\exp \left(-\tau_{870} / \cos \theta_{z}\right)\right)}{\cos \theta_{z}} \\
& \left.+c_{3} \frac{I_{\mathrm{dir}} / 1367\left(1-\exp \left(-\tau_{440} / \cos \theta_{z}\right)\right)}{\cos \theta_{z}^{2}}+c_{4} I_{\text {diff }} / 1367\right] .
\end{aligned}
$$

For convenience, the radiant flux densities (in $\mathrm{W} \mathrm{m}^{-2}$ ) are normalized with the solar constant $1367 \mathrm{~W} \mathrm{~m}^{-2}$ in order to obtain regression coefficients of roughly equal magnitude. It is noted that when applying this equation, the measured solar radiant flux density values are input as such without any correction for the varying Sun-Earth distance. The regression parameter values $c_{i}$ are given in Table 2, and the coefficient of determination for the regression was 0.999 when all $\tau_{440}$, $\tau_{870}, \theta_{z}$, ozone and water vapour amount values and all spectra were included. The correction term reduces to $c_{0}$, when $I_{\text {diff }}=0, \tau_{440}=0$ and $\tau_{870}=0$; the value of $c_{0}>1$, which is due to a small contribution from Rayleigh scattering. With no atmospheric effect $c_{0}$ would be exactly 1 . Regression
Table 2. The values of the regression parameters for the empirical relationship of Eq. (10) between the simulated pyranometer measured broadband surface albedo and the corresponding broadband black-sky albedo.

\begin{tabular}{lrrrrr}
\hline $\begin{array}{l}\text { Regression } \\
\text { parameter }\end{array}$ & All & Grass & Forest & $\begin{array}{r}\text { Mixtures } \\
\text { of rock }\end{array}$ & $\begin{array}{r}\text { Water, snow } \\
\text { and ice }\end{array}$ \\
\hline$c_{0}$ & 1.0127 & 1.0223 & 1.0137 & 1.0097 & 0.9316 \\
$c_{1}$ & 0.0159 & -0.1044 & -0.0755 & -0.0109 & -0.0105 \\
$c_{2}$ & 0.0299 & 0.0851 & 0.0911 & 0.0457 & 0.0412 \\
$c_{3}$ & -0.0643 & -0.0366 & -0.0350 & -0.0296 & 0.1029 \\
$c_{4}$ & -0.372 & -0.157 & -0.312 & -0.271 & -0.290 \\
\hline
\end{tabular}

parameter values were also derived for subsets of certain targets: (1) grass, (2) forest, (3) water, snow and ice and (4) mixtures of rock. For all other targets than water, snow and ice, the parameter $c_{0}$ is slightly larger than unity, as expected. For water, snow and ice, the functional form of Eq. (10) is not optimal. This is understandable because the snow and ice spectra are the only ones for which the reflectance essentially decreases with increasing wavelength. As the characteristics of the snow spectrum vary over a wide range depending on impurities and water content (Warren and Wiscombe, 1980; Wiscombe and Warren, 1980), the available snow spectra are not considered sufficiently representative to suggest deriving a snow specific set of regression parameters.

Equation (10) is written so that it uses both AOD and the direct and diffuse flux density values, because often they are measured independently. Another alternative to use this regression formula is to estimate the direct and diffuse flux density values from the AOD as described in Sect. 2.1 (Bird and Riordan, 1986). In clear-sky conditions the diffuse radiation value may be so small that its measurement inaccuracy starts to deteriorate the albedo estimates based on Eq. (10). Also, the integration time of the measurements of AOD and the flux densities may differ so much that the measured values do not represent the same conditions. Then it is better to estimate the flux density values from the measured AOD values when using Eq. (10).

Using Eq. (10) for correction of measured albedo values requires simultaneous data of AOD, which is not always 

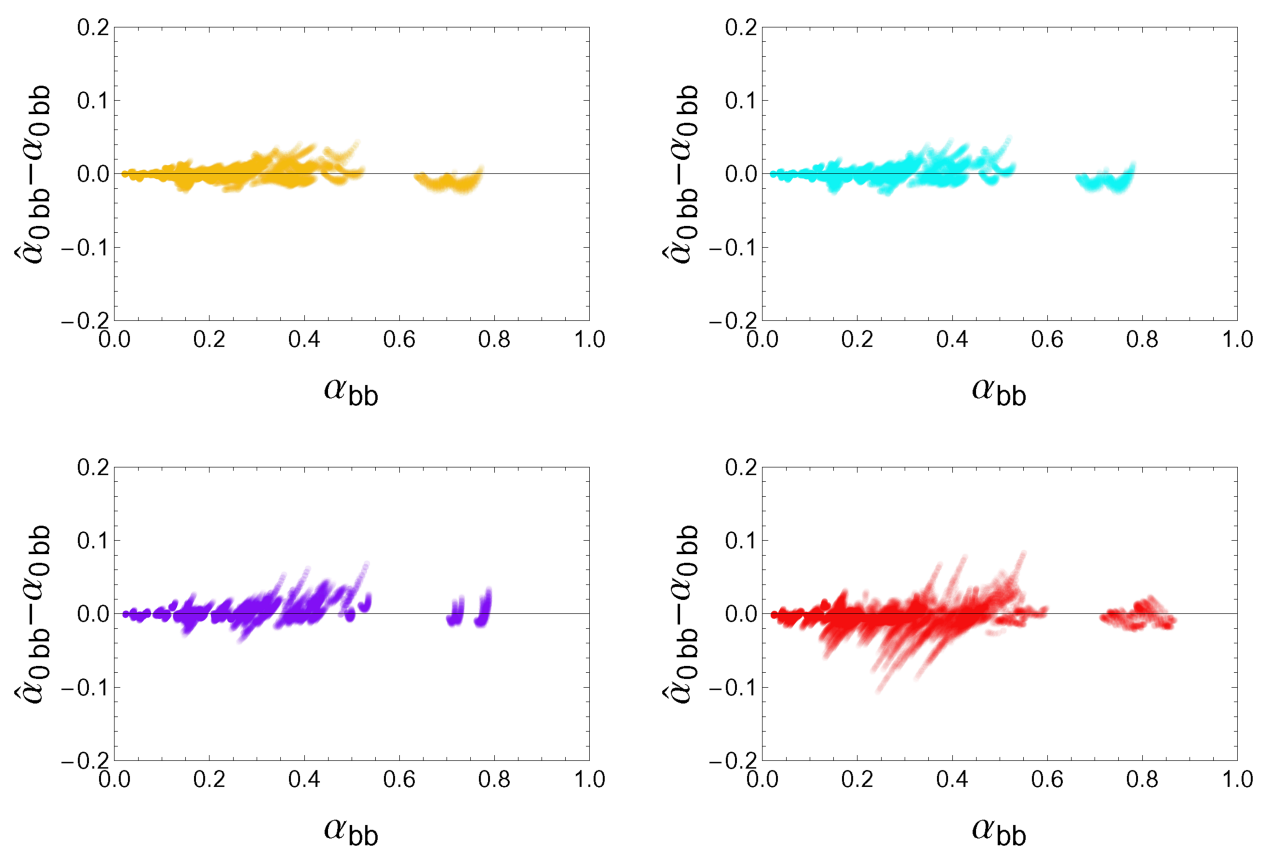

Fig. 5. Difference between the albedo estimate of the black-sky surface albedo $\hat{\alpha}_{0_{\mathrm{bb}}}$ based on the regression Eq. (10), and the black-sky albedo value $\alpha_{0_{\mathrm{bb}}}$ plotted as a function of the corresponding simulated blue-sky albedo $\alpha_{\mathrm{bb}}$ obtained using Eqs. (1) ... (8) for the 87 land cover type spectra used in all studied atmospheres and for the solar zenith angle values $0^{\circ}, 30^{\circ}, 50^{\circ}$ and $70^{\circ}$. The opacity of the points is related to the frequency of that value.

available. Therefore, another regression equation was derived for cases when only the (direct and diffuse) solar radiant flux density values are available for atmospheric correction:

$$
\begin{aligned}
\hat{\alpha}_{0_{\mathrm{bb}}=} & \alpha_{\mathrm{bb}}\left[d_{0}+d_{1} \log \left(I_{\mathrm{dir}} / 1367\right)\right. \\
& \left.\left(1-\exp \left(-0.1 / \cos \theta_{z}\right)\right)+d_{2} I_{\mathrm{diff}} / 1367\right] .
\end{aligned}
$$

The values for the regression coefficients $d_{0}, d_{1}$ and $d_{2}$ are given in Table 3. The coefficient of determination for this regression was also 0.999 . It should be noticed that the simulated values of $I_{\text {diff }}$ are based on the AOD values, so the AOD information is included in this equation implicitly, though not explicitly. Again, separate parameter values are also given for the various targets. When applying this equation, the measured solar radiant flux density values are input as such without any correction for the varying Sun-Earth distance, which is used here only as a scaling factor to achieve reasonable size regression coefficients.

The black-sky albedo estimation (Eqs. 10 and 11) was applied to the studied land cover spectra and calculated direct and diffuse solar radiant fluxes. The results are presented in Fig. 5, which shows the absolute differences between the estimated and true black-sky albedos as function of the bluesky albedo. Figure 5 shows that the absolute differences are mostly quite small. The $90 \%$ relative error quantile is about $8 \%$. Comparison with Fig. 3 shows that also the relative differences are substantially reduced. The estimation accuracy decreases rapidly when the solar zenith angle exceeds $60^{\circ}$.
Table 3. The values of the regression parameters for the empirical relationship of Eq. (11) between the simulated pyranometer measured broadband surface albedo and the corresponding broadband black-sky albedo.

\begin{tabular}{lccccc}
\hline $\begin{array}{l}\text { Regression } \\
\text { parameter }\end{array}$ & All & Grass & Forest & $\begin{array}{c}\text { Mixtures } \\
\text { of rock }\end{array}$ & $\begin{array}{c}\text { Water, snow } \\
\text { and ice }\end{array}$ \\
\hline$d_{0}$ & 0.9842 & 0.9803 & 0.9721 & 0.9902 & 0.9620 \\
$d_{1}$ & -0.109 & -0.114 & -0.142 & -0.0981 & -0.0691 \\
$d_{2}$ & -0.241 & -0.237 & -0.339 & -0.225 & -0.304 \\
\hline
\end{tabular}

Equation (11) produces almost as good black-sky albedo estimates as Eq. (10), but for large solar zenith angles it is clearly poorer.

The mean and the relative mean difference of all atmospherically corrected and true black-sky albedo values are shown as solid red curves in Fig. 6 for Eqs. (10) and (11) using the general regression parameter values of Tables 2 and 3. The corresponding $90 \%$ quantile values for the difference and relative difference of the atmospherically corrected and true black-sky albedo values are shown in solid blue curves. The corresponding differences between the blue- and blacksky values are shown as dashed curves. Obviously Eq. (10) produces only slightly better black-sky albedo estimates than Eq. (11), but in both cases the atmospherically corrected albedo estimates are markedly closer to the black-sky values than the blue-sky albedo values. The reason that the correction is less important for the solar zenith angle value of 

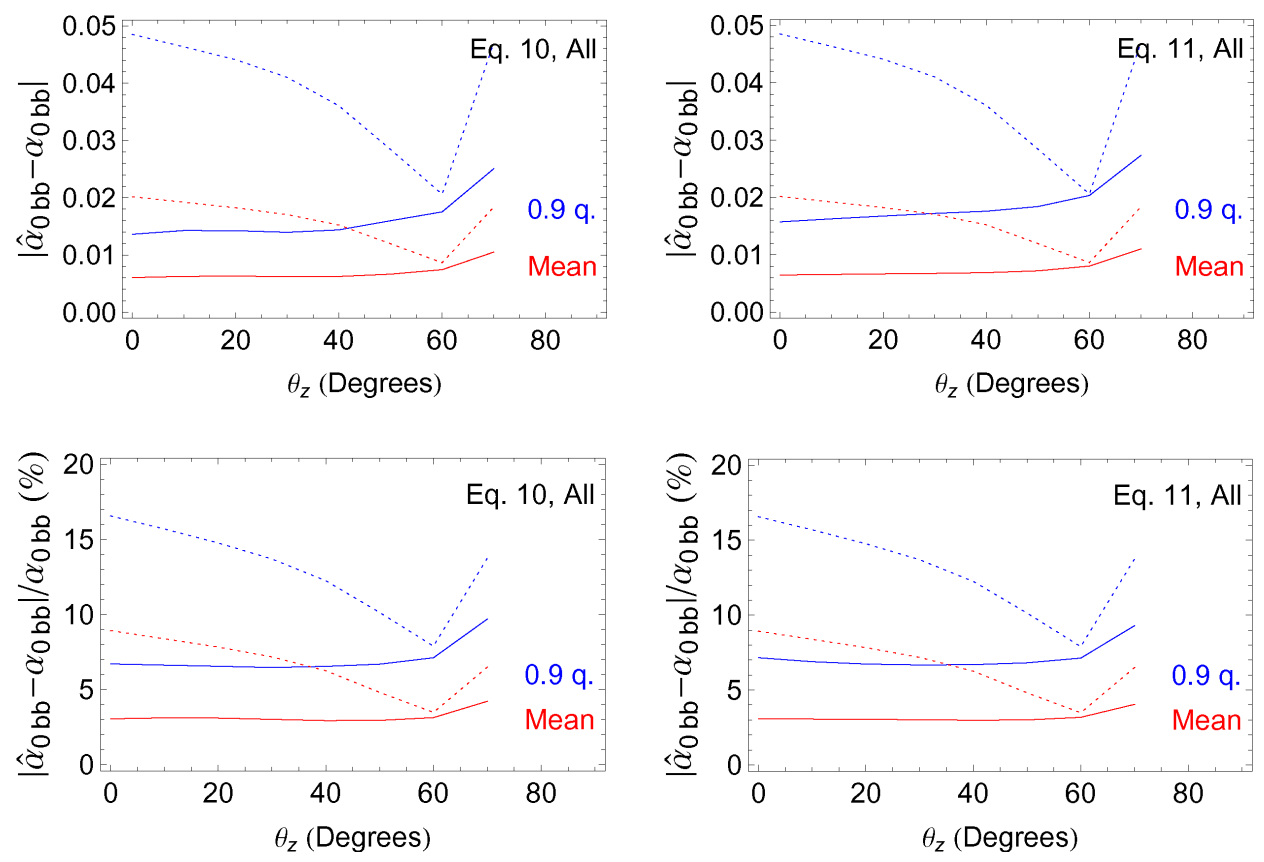

Fig. 6. Statistics for the difference (top panels) and relative difference (bottom panels) between the atmospherically corrected albedo $\hat{\alpha}_{0_{\mathrm{bb}}}$ and the calculated black-sky value $\alpha_{0_{\mathrm{bb}}}$ (solid curves) are shown as a function of the solar zenith angle for the regression Eqs. (10) (left panels) and (11) (right panels), using the general values for the regression parameters. For comparison, the deviation and relative deviation of the simulated (Eq. 1) blue-sky surface albedo $\alpha_{\mathrm{bb}}$ from the corresponding calculated black-sky value $\alpha_{0_{\mathrm{bb}}}$ (dashed curves) are shown as well. The mean and 0.9 quantile values are presented in each case. The curves are based on all 231768 individual combinations of 87 spectra, $37 \tau_{\text {Aer }}$ pairs, 3 ozone amount values, 3 water vapour values and 8 solar zenith angle values.

about $60^{\circ}$ is demonstrated by Fig. 3; the sign of the correction changes at about that solar zenith angle value.

The atmospherically corrected (black-sky) albedo estimate $\hat{\alpha}_{0_{\mathrm{bb}}}$ deviates from the black-sky value $\alpha_{0_{\mathrm{bb}}}$ by about 0.007 for both regression equations, whereas the uncorrected albedo $\alpha_{\mathrm{bb}}$ deviates from the black-sky value $\alpha_{0_{\mathrm{bb}}}$ by an average of 0.016 . The corresponding relative difference values are 3.2 and $6.7 \%$, respectively. However, more important is that the atmospheric correction removes large errors so that the deviation from the true value $\left|\alpha_{\mathrm{bb}}-\alpha_{0_{\mathrm{bb}}}\right|$ is on average in $90 \%$ of the cases smaller than 0.016 (Eq. 10) and 0.019 (Eq. 11) and the relative error is smaller than $7.1 \%$ (Eq. 10) and $7.2 \%$ (Eq. 11). For the uncorrected albedo $\alpha_{\mathrm{bb}}$, the corresponding deviations are 0.039 and $13 \%$. The largest difference between the simulated blue-sky albedo and the corresponding black-sky value was at nadir 0.11 , which was reduced to 0.044 (Eq. 10) and 0.066 (Eq. 11) by the atmospheric correction. Although large solar zenith angle values $\left(\sim 70^{\circ}\right)$ naturally are problematic for measurements (for cosine response, for example), it must be emphasized that the atmospheric effect is non-negligible also when the Sun elevation is high.

Using regression parameter values optimised for the target in question (Tables 2 and 3) naturally improved the results when applying Eqs. (10) and (11). For example, for grass the $90 \%$ quantile of the albedo difference was on average 0.0006 and the corresponding relative difference was $3.8 \%$. However, the number of individual spectra in each target class was so small $(10 \ldots 18)$ that it is difficult to determine how much of the improvement came from not having variation enough in the grass data set. Hence, it is considered safer to apply the general regression parameter values unless a large number of site specific spectra are measured outdoors in varying weather conditions for regression parameter retrieval. A site classified as grass may not always contain just grass. There may be dead leaves, snow or water pools on it, or the grass may be withered or burned.

\subsection{Cabauw data}

The method for estimating the effect of the atmosphere on the measured broadband albedo was tested with real data using simultaneous albedo, AOD and direct and diffuse solar radiant flux density measurements at Cabauw. The one minute averages of the diffuse and direct radiance and the 10 minute averages of the albedo closest to the AOD measurement time (every 15 minutes in clear-sky conditions) were chosen. The atmospherically corrected albedo values were obtained by application of Eq. (10) to the measured albedo. First, the calculations were carried out by estimating the solar direct and diffuse radiant flux density from the AOD data in the same way as in the simulation calculations. The results are 

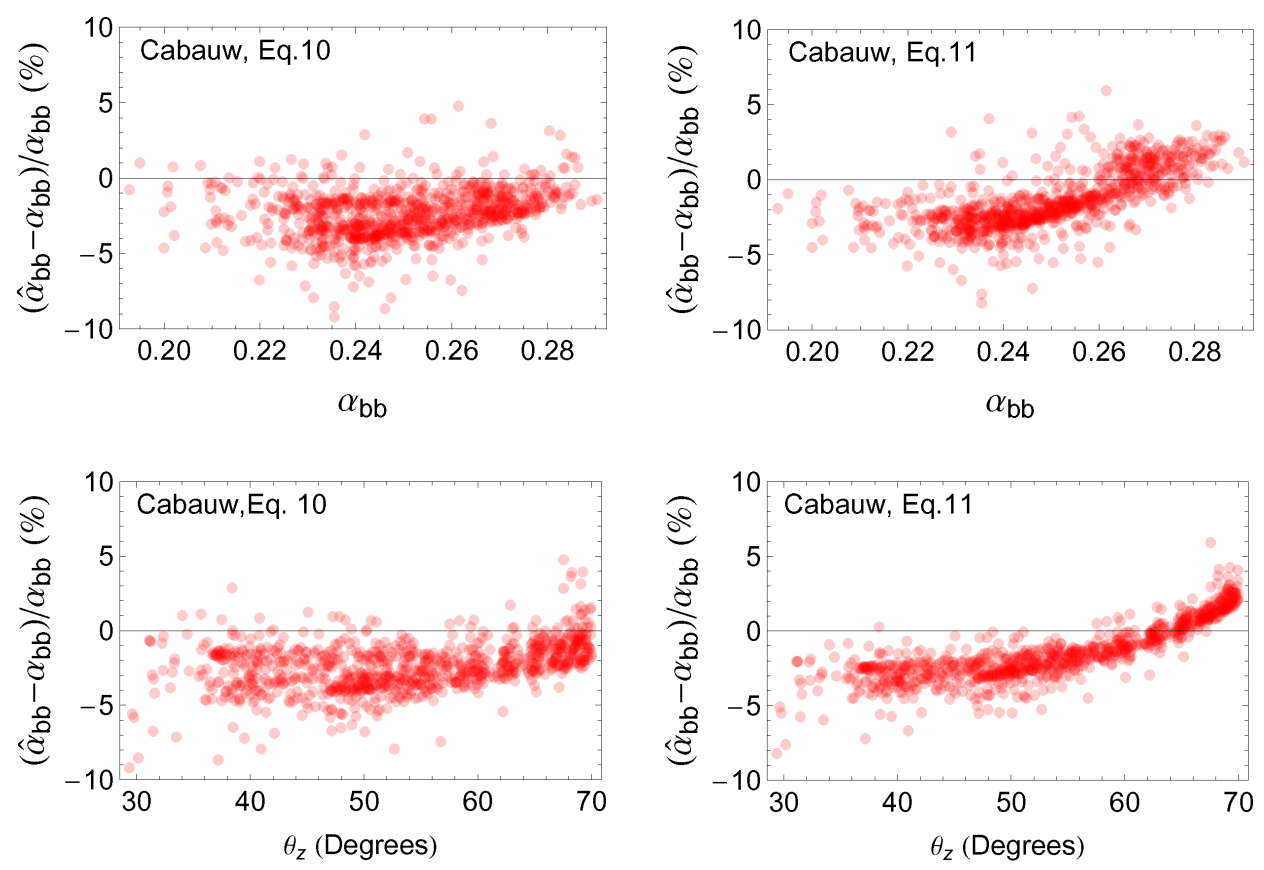

Fig. 7. Relative difference of the atmospherically corrected measured albedo $\hat{\alpha}_{0_{\mathrm{bb}}}$ and (uncorrected) measured albedo $\alpha_{\mathrm{bb}}$ values at Cabauw as a function of the measured albedo $\alpha_{\mathrm{bb}}$ (top panels) and the solar zenith angle (bottom panels). The corrections were carried out using Eqs. (10) (left panels) and (11) (right panels) with the general regression parameter values and measured $\tau_{\text {Aer }}$ values at $440 \mathrm{~nm}$ and $870 \mathrm{~nm}$. The opacity of the points is related to the frequency of the value.

presented in Fig. 7, which shows the relative differences between the atmospherically corrected and the measured values of the blue-sky surface albedo as function of the solar zenith angle. Figure 7 shows that due to the effect of the atmosphere the albedo $\alpha_{\mathrm{bb}}$ is overestimated by up to $5 \%$. The atmospheric correction decreased the average albedo from 0.25 to 0.24 , but the standard deviation increased at the same time from 1.8 to $1.9 \%$. It is noted that the albedo values were not normalized with respect to the solar zenith angle, and therefore some variation is due to differences in the solar zenith angle. Also, the change of season from February to July causes albedo variations due to biologically-induced (grass grows, mowing, grazing of sheep) and other changes of the surface characteristics. Using Eq. (11) instead of Eq. (10) produced albedo estimates closer to those measured. This is due to the fact that the simpler regression of Eq. (11) does not sufficiently compensate for large solar zenith angles (Fig. 7).

\section{Discussion}

When the measured direct and diffuse solar radiant flux density values were used in applying Eq. (11), the results were about the same as when they were estimated from the AOD values as shown in Figs. 8 and 9. Interestingly, the problem of large solar zenith angles was much reduced when measured values for the solar direct and diffuse radiant flux density were used. When Eq. (10) was applied, the scatter in the data

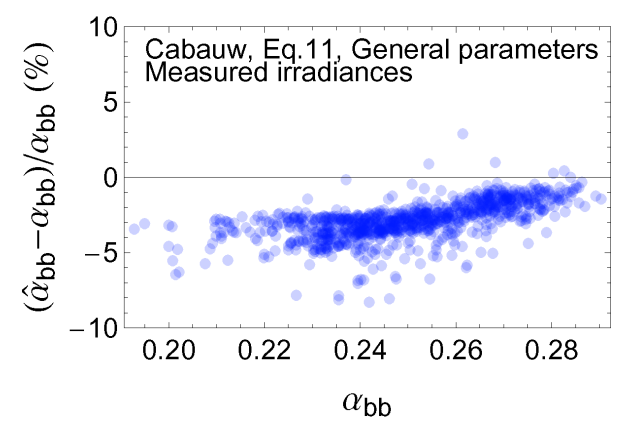

Fig. 8. Relative difference of the atmospherically corrected measured albedo $\hat{\alpha}_{0_{\mathrm{bb}}}$ and (uncorrected) measured albedo $\alpha_{\mathrm{bb}}$ values at Cabauw as a function of the measured albedo $\alpha_{\mathrm{bb}}$. The corrections were carried out using Eq. (11) with the general regression parameter values and measured direct and diffuse solar radiant flux density values. The opacity of the points is related to the frequency of the value.

increased somewhat, especially at the highest albedo values (which correspond to the largest solar zenith angle values). This may be caused by the slight temporal mismatch of the various measurements. The AOD values were provided irregularly with a time signature of seconds, and the direct and diffuse solar radiant flux density values were one minute averages, whereas the global and reflected radiation values were integrated over $10 \mathrm{~min}$. Thus, it is recommended to use either Eq. (10) with only AOD data (used also for retrieval of $I_{\text {dir }}$ 


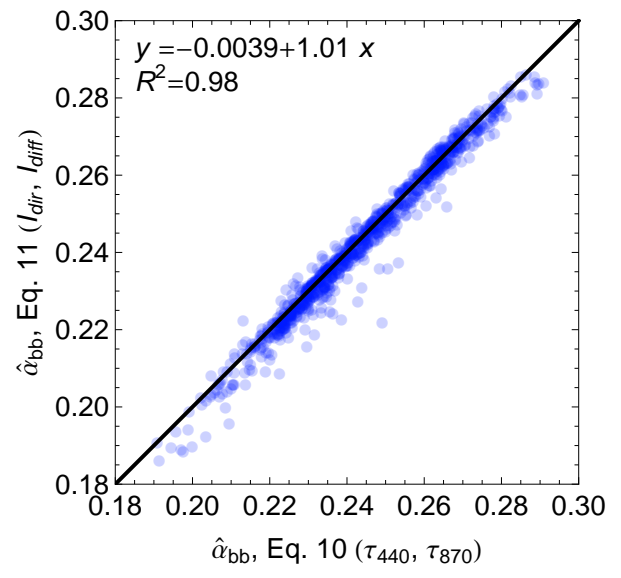

Fig. 9. Comparison of two atmospherically corrected albedo estimates $\hat{\alpha}_{0_{\mathrm{bb}}}$. The horizontal co-ordinate is based on Eq. (10) and measured albedo and AOD data, and the vertical co-ordinate is based on Eq. (11) and measured albedo, direct and diffuse radiant flux density values. The opacity of the points is related to the frequency of the value.

and $\left.I_{\text {diff }}\right)$ or Eq. (11) with measured direct and diffuse radiation. The small bias of 0.004 and almost unity slope (1.01) of the relationship between the two albedo estimates (Fig. 9), whose correction terms have different data sources (measured AOD or direct and diffuse solar radiant flux density), supports the choice of these two methods as reliable alternatives. The bias is related to large solar zenith angles, which are less well taken into account by the simpler Eq. (11). (The high value of the coefficient of determination is caused by internal correlation, because both albedo estimates are derived by multiplying the measured albedo by a correction factor.) For comparison, when the albedo estimates based on Eq. (11) would be calculated using AOD data, the corresponding relationship would be $y=-0.026+1.12 \cdot x$.

The atmospheric correction presented requires besides the normal pyranometer measurements (global radiant flux density and reflected radiation) only AOD values for at least two wavelengths to determine the spectral behaviour (Eq. 10). Preferably the wavelengths are 440 and $870 \mathrm{~nm}$ as used in the AOD measurements, but using Eq. (8) the AOD values for these wavelengths could also be estimated from two other wavelengths. No BRDF is needed when using the model. If measured values of the direct and diffuse solar radiant flux densities are available, they can be used. Otherwise, if the AOD is known, the direct solar radiant flux density can be calculated from the solar zenith angle and the solar constant using Eq. (6). Then the diffuse component is the difference of the measured global radiant flux density and the direct solar radiant flux density.

The regression parameters presented here were derived to be applicable to various kinds of land cover spectra. For permanent measurement sites, one might improve the accuracy by replacing the spectra used in the simulations with spectra specific for that site. Also, the solar zenith angle effect could be better taken into account if the regression parameters were derived separately for all angles. (However, the number of individual points is already large and each additional angle would require calculation of 28971 individual points.) Yet, the current method with constant coefficient values can be applied to estimate the magnitude of the effect of the atmosphere on the broadband surface albedo measurements, independent of any satellite data. Climatological AOD characteristics could be used instead of Sun photometer measurements to estimate the site-specific atmospheric effect.

\section{Conclusions}

The effect of the atmosphere on the measured broadband surface albedo can be as high as $20 \%$ (relative). The magnitude of the error depends on the solar zenith angle and the aerosol optical depth. When the solar zenith angle is about $60^{\circ}$, the various effects of the atmosphere tend to compensate each other, so that the blue-sky albedo value is closer to the blacksky albedo value than when the solar zenith angle is smaller or larger than that.

A robust method was developed for estimating the effect of the atmosphere on broadband surface albedo values measured using ground-based pyranometers. The input values needed are the global and reflected radiation values and aerosol optical depth values at two wavelengths. Alternatively, it is possible to use the direct and diffuse solar radiant flux density data instead of the aerosol optical depth values. The accuracy decreases with increasing solar zenith value for both alternatives. The average accuracy for blacksky albedo estimation based on albedo and AOD data was estimated to be 0.007 , and in $90 \%$ of the cases it is on average 0.016 . When using measured direct and diffuse solar radiant flux density values instead, the albedo estimation accuracy is about the same.

Although the method was developed in response to requirements for validation of satellite-based albedo estimates, it is not dependent on any satellite instrument. It provides a possibility to separately study the effect of the atmosphere on the surface albedo estimation without the complication of the heterogeneity of land cover, which is always problematic when using satellite data for albedo estimation.

Acknowledgements. The authors thank Fred Bosveld and Wouter Knap (KNMI, De Bilt, The Netherlands) for the Cabauw surface albedo data. The AOD data made available by AERONET is gratefully acknowledged. The work was financially supported by EUMETSAT in the project Satellite Application Facility on Climate Monitoring.

Edited by: M. Wendisch 


\section{References}

Ångström, A.: On the Atmospheric Transmission of Sun Radiation and on Dust in the Air, Geogr. Ann., 11, 156-166, 1929.

ASTM Standard G173-03: Standard Tables for Reference Solar Spectral Irradiances: Direct Normal and Hemispherical on a 37 Tilted Surface, 1992.

Bird, R. E. and Riordan, C.: Simple Solar Spectral Model for Direct and Diffuse Irradiance on Horizontal and Tilted Planes at the Earth's Surface for Cloudless Atmospheres, J. Clim. Appl. Meteorol., 25, 87-97, 1986.

Carrer, D., Geiger, B., Roujean, J.-L., Hautecoeur, O., Cedilnik, J., Mahfouf, J.-F., Meurey, C., and Franchisteguy, L.: Land surface albedo from MSG/SEVIRI: Retrieval method, validation, and application for weather forecast, Proc. IGARSS'09 IV, Le Cap, Afrique du Sud, 288-291, 2009.

Clark, R. N., Swayze, G. A., Wise, R., Livo, E., Hoefen, T., Kokaly, R., and Sutley, S. J.: USGS digital spectral library splib06a: US Geological Survey, Digital Data Series 231, http://speclab.cr. usgs.gov/spectral.lib06, last access: 12 November 2012, US Geological Survey, Denver Federal Center Denver, 2007.

Govaerts, Y. M., Pinty, B., Taberner, M., and Lattanzio, A.: Spectral Conversion of Surface Albedo Derived From Meteosat First Generation Observations, IEEE Geosci. Remote Sens. Lett., 3, 23-27, 2006.

Gueymard, C.: SMARTS, A Simple Model of the Atmospheric Radiative Transfer of Sunshine: Algorithms and Performance Assessment, Professional Paper FSEC-PF-270-95, Florida Solar Energy Center, Cocoa, 1995.

Gueymard, C.: Parameterized Transmittance Model for Direct Beam and Circumsolar Spectral Irradiance, Solar Energy, 71, 325-346, 2001.

Holben, B. N., Eck, T. F., Sluster, I., Tanré, D., Buis, J. P., Setzer, A., Vermote, E., Reagan, J. A., Kaufman, Y. J., Nakajima, T., Lavenu, F., Jankowiak, I., and Smirnov, Z.: AERONET - A Federated Instrument Network and Data Archive for Aerosol Characterization, Remote Sens. Environ., 66, 1-16, 1998.

Kaskaoutis, D. G. and Kambezidis, H. D.: The diffuse-to-global and diffuse-to-direct-beamspectralirradianceratios as turbidityindexes in an urbanenvironment, J. Atmos. Sol.-Terr. Phy., 71, 246-256, 2009.

Knap, Wouter: http://www.knmi.nl/bsrn/, last access: 12 November 2012.

Knap, Wouter: Basic measurements of radiation at station Cabauw (2007-03), Koninklijk Nederlands Meteorologisch Instituut, De Bilt, doi:10.1594/PANGAEA.758380, 2011.

Lewis, P. and Barnsley, M. J.: Influence of the sky radiance distribution on various formulations of the Earth surface albedo, in: Proc. Conf. Phys. Meas. Sign. Remote Sens., Val d'Isere, France, 707-715, 1994.

Liang, S., Shuey, C. J., Russ, A. L., Fang, H., Chen, M., Walthall, C. L., Daughtry, C. S. T., and Hunt Jr., R.: Narrowband to broadband conversions of land surface albedo, II. Validation, Remote Sens. Environ., 84, 25-41, 2002.

Lucht, W., Hyman, A. H., Strahler, A. H., Barnsley, M. J., Hobson, P., and Muller, J.-P.: A Comparison of Satellite-Derived Spectral Albedos to Ground-Based Broadband Albedo Measurements Modeled to Satellite Spatial Scale for a Semidesert Landscape, Remote Sens. Environ., 74, 85-98, 2000a.
Lucht, W., Schaaf, C. B., and Strahler, A. H.: An Algorithm for the Retrieval of Albedo from Space Using Semiempirical BRDF Models, IEEE T. Geosci. Remote, 38, 977-998, 2000 b.

Lyapustin, A., Martonchik, J., Wang, Y., Laszlo, I., and Korkin, S.: Multiangle implementation of atmospheric correction (MAIAC): 1. Radiative transfer basis and look-up tables, J. Geophys. Res., 116, D03210, doi:10.1029/2010JD014985, $2011 \mathrm{a}$.

Lyapustin, A., Wang, Y., Laszlo, I., Kahn, R., Korkin, S., Remer, L., Levy, R., and Reid, J. S.: Multiangle implementation of atmospheric correction (MAIAC): 1. Aerosol algorithm, J. Geophys. Res., 116, D03211, doi:10.1029/2010JD014986, 2011 b.

Manninen, T. and Riihelä, A.: Atmospheric effect on validation of broadband surface albedo (SAL) product of CM SAF using mast measurements, EUMETSAT Meteorological satellite conference, 8-12 September 2008, Darmstadt, CD, p. 8, 2008.

Marsden, D. C., Valero, F. P. J., and Bush, B. C.: Continental aerosol properties inferred from measurements of direct and diffuse solar irradiance, J. Geophys. Res., 110, D20204, doi:10.1029/2004JD005660, 2005.

Martonchik, J. V., Diner, D. J., Pinty, B., Verstraete, M. M., Myneni, R. B., Knyazikhin, Y., and Gordon, H. R.: Determination of land and ocean reflective, radiative, and biophysical properties using multiangle imaging, IEEE T. Geosci. Remote, 36, 1266-1281, 1998.

Michalsky, J. J., Harrison, L. C., and Berkheiser III, W. E. Cosine response characteristics of some radiometric and photometric sensors, Solar Energy, 54, 397-402, 1995.

Nicodemus, F. E.: Reflectance nomenclature and directional reflectance and emissivity, Appl. Optics, 9, 1474-1475, 1970.

Ohmura, A., Dutton, E., Forgan, B., Frohlich, C., Gilgen, H., Hegne, H., Heimo, A., Konig-Langlo, G., McArthur, B., Muller, G., Philipona, R., Whitlock, C., Dehne, K., and Wild, M.: Baseline Surface Radiation Network (BSRN/WCRP): New precision radiometery for climate change research, B. Am. Meteorol. Soc., 79, 2115-2136, 1998.

Peltoniemi, J. I., Manninen, T., Suomalainen, J., Hakala, T., Puttonen, E., and Riihelä, A.: Land Surface Albedos Computed from BRF Measurements with a Study of Conversion Formulae, Remote Sens., 2, 1918-1940, doi:10.3390/rs2081918, 2010.

Pinty, B. Lattanzio, A., Martonchik, J. V., Verstraete, M. M., Gobron, N., Taberner, M., Widlowski, J.-L., Dickinson, R., and Govaerts, Y.: Coupling Diffuse Sky Radiation and Surface Albedo, J. Atmos. Sci., 62, 2580-2591, 2005.

Pinty, B., Lavergne, T., Voßbeck, M., Kaminski, T., Aussedat, O., Giering, R., Gobron, N., Taberner, M., Verstraete, M. M., and Widlowski, J.-L.: Retrieving surface parameters for climate models from Moderate Resolution Imaging Spectroradiometer (MODIS) - Multiangle Imaging Spectroradiometer (MISR) albedo products, J. Geophys. Res., 112, D10116, doi:10.1029/2006JD008105, 2007.

Rahman, H. and Dedieu, G.: SMAC: A simplified method for the atmospheric correction of satellite measurements in the solar spectrum, Int. J. Remote Sens., 15, 123-143, doi:10.1080/01431169408954055, 1994.

Raïch, A., González, J. A., and Calbó, J.: Effects of solar height, cloudiness and temperature on silicon pyranometer measurements, Tethys, 4, 11-18, 2007. 
Riihelä, A., Laine, V., Manninen, T., Palo, T., and Vihma, T.: Validation of the Climate-SAF surface broadband albedo product: Comparisons with in situ observations over Greenland and the ice-covered Arctic Ocean, Remote Sens. Environ., 114, 27792790, 2010.

Román, M. O., Schaaf, C. B., Lewis, P., Gao, F., Anderson, G. P., Privette, J. L., Strahler, A. H., Woodcock, C. E., and Barnsley, M.: Assessing the coupling between surface albedo derived from MODIS and the fraction of diffuse skylight over spatiallycharacterized landscapes, Remote Sens. Environ., 114, 738-760, 2010.

Roujean, J.-L., Leroy, M., and Deschamps, P.-Y.: A Bidirectional Reflectance Model of the Earth's Surface for the Correction of Remote Sensing Data, J. Geophys. Res., 97, 20455-20468, 1992.

Schaepman-Strub, G., Schaepman, M. E., Painter, T. H., Dangel, S., and Martonchik, J. V.: Reflectance quantities in optical remote sensing - definitions and case studies, Remote Sens. Environ., 103, 27-42, 2006.

Schulz, J., Albert, P., Behr, H.-D., Caprion, D., Deneke, H., Dewitte, S., Dürr, B., Fuchs, P., Gratzki, A., Hechler, P., Hollmann, R., Johnston, S., Karlsson, K.-G., Manninen, T., Müller, R., Reuter, M., Riihelä, A., Roebeling, R., Selbach, N., Tetzlaff, A., Thomas,
W., Werscheck, M., Wolters, E., and Zelenka, A.: Operational climate monitoring from space: the EUMETSAT Satellite Application Facility on Climate Monitoring (CM-SAF), Atmos. Chem. Phys., 9, 1687-1709, doi:10.5194/acp-9-1687-2009, 2009.

Strahler, A. H., Lucht, W., Schaaf, C. B., Tsang, T., Gao, F., Li, X., Muller, J.-P., Lewis, P., and Barnsley, M. J.: MODIS BRDF/Albedo Product: Algorithm Theoretical Basis Document NASA EOS-MODIS document, v5.0, NASA Goddard Space Flight Cent., Greenbelt, Md., p. 53, 1999.

Warren, S. G. and Wiscombe, W. J.: A Model for the Spectral Albedo of Snow, I: Snow Containing Atmospheric Aerosols, J. Atmos. Sci., 37, 2734-2745, 1980.

Wiscombe, W. J. and Warren, S. G.: A model for the spectral albedo of snow, I: Pure Snow, J. Atmos. Sci., 37, 2712-2733, 1980.

WCRP: Summary report from the 9th session of the Baseline Surface Radiation Network (BSRN), 29 May-2 June 2006, WCRP informal report No. 1/2007, Lindenberg, Germany, p. 54, 2007.

Wu, A., Li, Z., and Cihlar, Z.: Effects of land cover type and greenness on advanced very high resolution radiometer bidirectional reflectances: Analysis and removal, J. Geophys. Res., 100, 9179 9192, 1995. 